\title{
Presencia escondida de Dios en el centro del alma. Reflexiones sobre la antropología mística de San Juan de la Cruz*
}

Lucero González Suárez

Recibido: 12 de marzo de 2016 - Aprobado: 15 de mayo de 2016

\section{Resumen}

Este artículo es una reflexión filosófica sobre los rasgos esenciales de aquella estructura del ser del hombre donde se halla escondida la presencia esencial de Dios: el centro del alma. La tesis por demostrar es que la condición de posibilidad de la unión mística es la presencia escondida de Dios en el centro del alma. Comienzo por explicar que la antropología mística de san Juan de la Cruz se distingue tanto de la teodicea como de la teología y de la psicología. Posteriormente, muestro que tanto el ser como la existencia del hombre tienen su principio en Dios. A continuación, argumento que el deseo que origina el comienzo del proceso místico hunde sus raíces en la presencia de Dios en el centro del alma. Finalmente, hablo de los dos posibles modos de vida que el hombre puede adoptar: la existencia carnal y la espiritual.

Palabras clave: antropología, mística, san Juan de la Cruz, alma, hombre, Dios.

Artículo de reflexión. Este trabajo fue realizado en el marco del segundo año de la estancia que la autora realizó en la Universidad Iberoamericana, con el apoyo del programa de Becas para Estancias Posdoctorales Nacionales, del Consejo Nacional de Ciencia y Tecnología. DOI: http://dx.doi.org/10.15332/s0120-8454.2016.0089.06

" Doctora en Filosofía de la Universidad Nacional Autónoma de México (UNAM). Profesora asociada "C" de tiempo completo, para la Licenciatura en Filosofía, División de Humanidades, Facultad de Estudios Superiores Acatlán, UNAM, área de Antropología Filosófica. Dirección postal: calle Centenario \# 457, departamento 701, colonia barrio Nextengo, Delegación Azcapotzalco. Código postal 02070, México, Distrito Federal. Correo electrónico: noche_oscura27@yahoo. com.mx. 


\section{The hidden presence of God in the center of the soul. Reflections on the mystique anthropology of Saint John of the Cross*}

Lucero González Suárez**

\section{A bstract}

This article is a philosophical reflection on the essential features of that structure of the human being in which the essential presence of God is hidden: the center of the soul. It is intended to demonstrate that the condition of possibility of mystical union is the hidden presence of God in the center of the soul. In the first section I explained that the mystical anthropology of John of the Cross is distinguished both of theodicy and theology and psychology. Later, I show that both being and the existence of man are founded in God. Then, I argue that desire, which is the beginning of the mystical process, is rooted in the presence of God in the center of the soul. Finally, I talk about the two possible ways of life that man can take: the carnal and spiritual existence.

Keywords: Anthropology, mysticism, Saint John of the Cross, soul, men, God.

Reflection paper. This work was performed during the second year of the academic stay of the author in Universidad Iberoamericana, with the support of the Postdoctoral Stay Scholarship National Program, from the National Council of Science and Technology. DOI: http://dx.doi.org/10.15332/s0120-8454.2016.0089.06

" Doctor of Philosophy at Universidad Nacional Autónoma de México (UNAM). Full-time "C" Associate Professor for the Degree in Philosophy, Division of Humanities, Faculty of Higher Education Acatlán, UNAM, Philosophical Anthropology area. Address: Calle Centenario \# 457, department 701, Nextengo colony neighborhood, Azcapotzalco. Postal code 02070, Mexico, Federal District. Email: noche_oscura27@yahoo.com.mx. 


\section{Présence de Dieu cachée dans le centre de l'âme. Réflexions sur l'anthropologie mystique de San Jean de la Croix*}

Lucero González Suárez

\section{Résumé}

Cet article est une réflexion philosophique sur les traits essentiels de cette structure de l'être de l'homme où l'on trouve cachée la présence essentielle de Dieu : le centre de l'âme. La thèse à démontrer est que la condition de possibilité de l'union mystique est la présence cachée de Dieu dans le centre de l'âme. Je commence par expliquer que l'anthropologie mystique de Saint Jean de la Croix se distingue tant de la théodicée comme de la théologie et de la psychologie. Par la suite, je montre que tant l'être comme l'existence de l'homme ont leur commencement en Dieu. Ensuite, j' argumente que le désir qui est à l'origine du commencement du processus mystique enfonce ses racines dans la présence de Dieu dans le centre de l'âme. Finalement, je parle des deux possibles modes de vie que l'homme peut choisir : l'existence charnelle et la spirituelle.

Mots clés: Anthropologie, mystique, Saint Jean de la Croix, âme, homme, Dieu.

Article de réflexion. Ce travail a été réalisé dans le cadre de la deuxième année de séjour que l'auteur a réalisé à I'Université lberoaméricaine, avec le soutien du programme de Bourses pour Séjours de Post doctorats Nationaux du Conseil National de Science et Technologie. DOI: http://dx.doi.org/10.15332/s0120-8454.2016.0089.06

Docteur en Philosophie de I'Université Nationale Autonome du Mexique (UNAM). Professeur associée "C" à temps complet, pour le programme de Philosophie, Division de Sciences Humaines, Faculté d'Études Supérieures Acatlán, UNAM, département d'Anthropologie Philosophique. Adresse postale: calle Centenario \# 457, appartement 701, colonia barrio Nextengo, Delegación Azcapotzalco. Code postal 02070, Mexique, Distrito Federal. E-mail: noche_oscura27@ yahoo.com.mx. 


\section{Introducción}

El propósito de esta reflexión filosófica es mostrar los rasgos esenciales de aquella estructura del ser del hombre donde se halla escondida la presencia esencial de Dios: el centro del alma, al que san Juan de la Cruz (sjc) alude, principalmente, en la Subida del Monte Carmelo.

La tesis por demostrar es que la condición de posibilidad de la unión de semejanza amorosa, que sJc identifica con la felicidad y plenitud humanas, es la presencia escondida de Dios en el centro del alma. Presencia que el espiritual logra desocultar mediante la negación de los gustos, apetitos, asimientos e imperfecciones que la eclipsan, es decir, a través de aquellas prácticas y ejercicios ascéticos que tienen por fin la purificación de los sentidos y de las potencias del alma.

A fin de cumplir con dicho cometido, comenzaré por explicar que la antropología propuesta por sjc se distingue tanto de la teodicea como de la teología porque, lejos de consistir en un discurso secundario sobre lo divino, se origina en la contemplación amorosa de Dios. También se separa de la psicología, porque al hablar del hombre no lo reduce a mera conciencia, sino que considera la totalidad de su ser, en su dimensión de apertura a la trascendencia. Posteriormente, mostraré que tanto el ser como la existencia del hombre tienen su principio en Dios. A continuación, argumentaré que el deseo que origina el comienzo del proceso místico hunde sus raíces en la presencia esencial de Dios en el centro del alma. Finalmente, para responder a la posible objeción acerca de ¿cómo puede estar Dios en el centro del alma sin que nos percatemos de ello?, describiré los dos posibles modos de vida que el hombre puede adoptar: la existencia carnal y la espiritual. Esto me permitirá argumentar que aun cuando Dios está presente por esencia en el alma de todo hombre, su descubrimiento reclama como condición de posibilidad que este último se disponga favorablemente para encontrarla, a través de la adopción de prácticas ascéticas, cuyo propósito es eliminar aquello que eclipsa dicha presencia: los gustos y apetitos de la voluntad, asociados a la existencia carnal.

La importancia de esta reflexión procede tanto de la centralidad de la pregunta que la dirige - ¿qué es el hombre con relación a Dios? - como del hecho de que para responder a ella no se atiende a la experiencia del hombre promedio - que a la miseria ontológica de su ser le agrega, por cuenta propia, la ceguera derivada de su miseria moral y espiritual-, sino al testimonio de un hombre que, como sJc, alcanzó la plenitud derivada de la unión mística con Dios.

\section{La experiencia de Dios: principio y fundamento de la antropología sanjuanista}

¿De dónde procede la autoridad con la que sjc habla sobre Dios y sobre el hombre? Responder a tal interrogante supone comprender que el conocimiento 
místico no es el resultado de una búsqueda filosófica ni teológica. La antropología sanjuanista no es conocimiento natural, obtenido a través del comercio con los sentidos, ni del análisis racional de la revelación. Lo que el santo sabe del hombre, de Dios y del nudo inefable que los une se origina en la noticia sobrenatural de la fe; es efecto de la iluminación amorosa que, a manera de don, el Esposo Cristo ha infundido en el alma del hombre, para transformarlo y unirlo consigo.

Frente a los discursos de la teología y de la teodicea, que surgen respectivamente de la interpretación de los textos sagrados y del preguntar filosófico, la mística es experiencia sobrenatural de Dios. Como ha señalado un estudioso del fenómeno religioso, "se ha llamado 'teología' a este lenguaje secundario, en oposición al primario, que es atribuido a una fuente divina" (Martín, 2002, p. 229). Frente a la teología, la mística se distingue por ser un conocimiento que surge del contacto directo con lo divino, que el espiritual acoge pasivamente; que lejos de ser el resultado de una búsqueda intelectual, es efecto de un don infuso: la fe teologal. Lejos de ser una elaboración racional, el discurso del místico es resonancia de su encuentro personal con Dios. Por su parte, de acuerdo con José María Melero

La pregunta sobre Dios nace en el interior de la interrogación sobre el dolor, en la experiencia del límite ¿Por qué el dolor del mundo? ¿Por qué la finitud? ¿Por qué el silencio de la muerte? De la muerte, del temor a la muerte surge y se eleva el conocimiento sobre Dios. El pensamiento sobre Dios, la Teodicea. Esta se suele pensar desde el dolor, es hija del dolor. (2000, p. 79)

La teodicea permite conocer a Dios como causa y principio de la realidad, pero el ser de Dios no se agota en la Creación. Dios, como señaló san Anselmo en el Proslogion, no solo es "Aquello mayor que lo cual nada puede pensarse". Ante todo, es "aquello mayor que lo cual, nada puede ser pensado". De manera que aun cuando podemos afirmar que las criaturas son semejantes a Dios, entendido como causa eficiente, Dios no es semejante a las criaturas. En su momento, santo Tomás de Aquino aclaró lo anterior al advertir que

[...] la relación de semejanza entre las creaturas y Dios no es recíproca: las creaturas son semejantes a Dios; pero Dios no es semejante a las creaturas, "pues, como dice Dionisio en el c. 9 De Div. Nom., entre las cosas que son del mismo orden hay semejanza mutua, pero no entre la causa y lo causado; pues decimos que la imagen es semejante al hombre, no al revés. Así es como puede decirse que la criatura es semejante a Dios; no, sin embargo, que Dios sea semejante a la criatura. (González, 2015, p. 166)

Al plantearse la pregunta por el ser del ente, la teodicea comienza por distinguir ambos. No obstante, incurre en su confusión tan pronto sostiene que el ser es el fundamento del ente. Así establece una doble relación de dependencia, por obra de la cual el ente requiere del ser como principio de su esencia y existencia, mientras que el ser solo puede ser pensado como fundamento del ente. 
El pensar metafísico, propio de la teodicea, reconoce la diferencia entre el ser de lo ente para después olvidarse de ella, toda vez que no reconoce la necesidad y pertinencia de plantear la pregunta que interroga por el sentido del ser, en vez de lo cual se pregunta por el sentido de los entes. Se limita a preguntar por el principio que legitima o justifica la realidad óntica, al que también concibe en términos ónticos. Pregunta por el fundamento óntico de lo ente, que responde a su necesidad de fundamentación. (González, 2011, p. 126)

Lejos de concebir que entre ser y ente hay una diferencia real, y no solo de grado, la teodicea - o como Heidegger la llama, la metafísica onto-teológica - piensa al ser como un ente de mayor jerarquía, puesto que de no haber semejanza estructural entre uno y otro, el primero no podría explicar la especificidad del segundo.

Para la metafísica, el ser del ente contingente y finito solo puede justificarse gracias a la existencia de un principio absoluto. Dicho principio es una entidad de mayor jerarquía, a la que se identifica como causa eficiente tanto del acto de ser como de las determinaciones de las entidades finitas. A fin de salvaguardar su independencia y autonomía respecto de los bienes finitos, de los cuales es fundamento, tal entidad ha de permanecer ajena a la finitud: deberá ser trascendente. Mas al establecer dicha relación entre en ente y el ser (reducido a entidad absoluta), "se ha mencionado ya el concepto metafísico de Dios. La metafísica ha de ir a parar a Dios con el pensamiento, porque el asunto del pensamiento es el ser, y éste está presente de muchas maneras como fundamento" (Heidegger, 1988, p. 131).

Al decir lo anterior, lo que Heidegger pretende mostrar es que el concepto metafísico de Dios hace de este un principio absoluto y trascendente, que es fundamento de los entes. Principio que, no obstante, comparte con ellos su estatus ontológico: es una entidad; pero absoluta y perfectísima, cuya existencia no supone una causa eficiente. Tal reducción provoca la desdivinización de Dios, por cuanto lejos de abrir la posibilidad de comprender que, como ha señalado Juan Martí Velasco, Dios es una presencia inobjetiva, sostiene que es un ente. A su vez, esto deriva en el ocultamiento de que, lejos de ser entidad u objeto de la reflexión calculadora, Dios es misterio. Lo más sorprendente es que, como Heidegger advierte,

Este golpe no viene de los insensatos que no creen en Dios, sino de los creyentes y sus teólogos, los cuales hablan del ente más ente de todos los entes sin que se les ocurra pensar en el ser mismo, para comprender de este modo, por poco que se metan en la teología de la fe, que este pensar y este hablar, vistos desde la misma fe, son blasfemia. (Heidegger, 2001, pp. 216-217)

La teodicea se empeña en demostrar la existencia del ente Dios. Una vez satisfecha tal exigencia, su tarea es preguntarse por sus atributos esenciales; decidir si es posible conocerlo y, de ser el caso, de qué manera. El Dios "de los filósofos" 
es el correlato de un concepto y, por ende, es el resultado de un proceso de abstracción y subjetivación.

En franca oposición a la teodicea, el Dios del que habla el místico no es un concepto ni una representación; es el término que origina y funda una experiencia transformadora. A fin de comprender la distancia entre la comprensión que la teodicea tiene de Dios y la experiencia que el místico tiene de Dios en tanto que presencia, es importante atender a las palabras de Gabriel Marcel, cuando nos dice que una presencia
Únicamente puede aceptarse (o rechazarse); pero es evidente que entre aceptar y captar, la diferencia de actitud es fundamental... no puedo aceptar algo que sea pura y simplemente un objeto, que no puedo más que tomar o dejar donde está. Es evidente que aquí la expresión "tomar" se refiere también al trabajo de la inteligencia, es decir, en suma, al comprender. (1964, p. 169)

Para el místico, Dios no es una entidad; es un acontecimiento salvador, que se le entrega como presencia. Cuando tiene lugar, la manifestación velada de la presencia divina se impone al hombre con la fuerza de la experiencia. Es válido dudar si a determinado concepto corresponde algo. Pero cuando se participa en la donación de un misterio, que por lo tanto envuelve la propia existencia, la duda ya no tiene cabida.

Para sjc, la mística no es una experiencia extraordinaria - accesible solo a algunos cuantos "elegidos" - , derivada de un estado alterado de consciencia. De ahí que al referirse a la repercusión de la experiencia de Dios, tanto en los sentidos como en la afectividad, lo haga solo para dejar en claro que así como el Misterio de Dios no se puede reducir al concepto filosófico-teológico Dios; tampoco es posible identificar sin más el sentimiento de su cercanía ni el de su ausencia con la presencia por gracia de Dios. Puesto que Dios no es una idea ni un sentimiento - oceánico, infinito, sobrenatural o como sea que se le quiera llamar-, no es apropiado tomar la afectividad como criterio último ni único para atestiguar el carácter auténtico o espurio de la experiencia de Dios. Para el santo, psicología y mistagogía no son dimensiones de la experiencia que deban disociarse, ya que de lo contrario, se dejan a un lado los criterios según los cuales cabe identificar el carácter auténtico o espurio de la experiencia mística.

Las guías espirituales de sjc no son manuales; su propósito no es enseñar el arte de emplazar el acontecer de la presencia divina. El modo en que la gracia opera en cada individuo se acomoda a su peculiar condición y situación vital. Aun siendo uno el camino de perfección, no todos lo recorren exactamente del mismo modo ni al mismo tiempo. Por ello, al anunciar el propósito de sus libros, sjc señala que su deseo es dar "luz general" sobre la experiencia de la unión amorosa. Considera que lejos de acotar de una vez y para siempre el sentido de los "dichos de amor", compuestos bajo la inspiración de la inteligencia mística, conviene más "dejarlos en su anchura, para que cada uno de ellos se aproveche 
según su modo y caudal de espíritu, que abreviarlos a un sentido a que no se acomode todo paladar" (2003a, p. 2).

En contra de quienes definen a sJc como un elevado psicólogo, considero más apropiado hablar de él como mistagogo: como un hombre que, tras haber alcanzado la cima de la contemplación amorosa, se esforzó en buscar las palabras apropiadas para transmitir la hermosura, la belleza y la perfección de la vida que participa del amor que Dios es.

En vez de hablar de la realidad Dios, en términos ónticos, el discurso de sJc da cuenta de la manera en que tiene lugar la experiencia del Dios de la revelación y del hombre como ser para Dios. El legado del santo consiste en una teología y una antropología místicas; no en una teología, una teodicea ni una psicología de la conciencia mística. Su testimonio nos ha permitido comprender que por encima de toda representación conceptual, Dios es una presencia misteriosa que dispensa al hombre la salvación, al conducirlo a la unión mística. Es decir, que el Amado Esposo Cristo es una Persona que, a lo largo de las generaciones, sale al encuentro de cada hombre, llamándolo por su nombre, para convocarlo a la vida eterna. Una manera de comprender el proceso místico consiste en reconocer que

[...] a lo largo de la búsqueda [que el espiritual emprende para unirse a la presencia divina] puede detectarse una paulatina transformación del concepto de la deidad [...] a la par que una transformación en la concepción del propio sujeto de la mística. (Cabrera, 2006, p. 11)

En suma, mientras que la teología y la teodicea son discursos secundarios sobre lo divino, que se refieren a Dios como el concepto que significa el término de la experiencia religiosa y el Ente perfectísimo de donde procede toda entidad particular, la mística, al igual que la revelación, es un discurso originario, cuya autoridad procede de la experiencia de Dios, que tiene por condición de posibilidad la manifestación de su presencia. Manifestación que va ganando en claridad y esencialidad, conforme el hombre progresa en la negación de las imperfecciones morales y espirituales que le impiden acceder al encuentro con el Dios vivo y verdadero.

\section{El hombre: finitud sostenida por un principio sin principio}

Que Dios es trascendente es una verdad revelada. Más aun, para la fenomenología es claro que "Todo misticismo es, en esencia - bien que realizado en grados distintos - , identificación con lo trascendente" (Otto, 2007, p. 33). Sin embargo, para disipar algunas confusiones, conviene apuntar que la noción de trascendencia no significa que Dios habite en un más allá, en una ubicación espacial lejana respecto de las criaturas. Dios es trascendente en el sentido de 
que, lejos de identificarse con el ser de lo finito, su presencia en las cosas y en el hombre es aquello que lo sostiene en el ser. Dios es el principio de la vida. Tanto la revelación como la mística enseñan que Dios es el fundamento sin fundamento de lo que es. ${ }^{1}$

Él creó, de un solo principio, todo el linaje humano, para que habitase sobre la faz de la tierra fijando los tiempos determinados y los límites del lugar donde habían de habitar, con el fin de que buscasen la divinidad, para ver si a tientas la buscaban y la hallaban; por más que no se encuentra lejos de cada uno de nosotros; pues en él vivimos, nos movemos y existimos. (Hch 17, 26-28)

El Dios de la revelación, a diferencia del Dios de la filosofía, no es una entidad ajena e indiferente al mundo, a la que es preciso recurrir para explicar la realidad contingente. Al explicar el sentido místico de la trascendencia de Dios, sJC sostiene:

Dios en cualquier alma, aunque sea la del mayor pecador el mundo, mora y asiste sustancialmente. Y esta manera de unión siempre está hecha entre Dios y las criaturas todas, en la cual les está conservando el ser que tienen; de manera que si [de ellas] desta manera faltase, luego se aniquilarían. (2003d, pp. 2, 5, 3)

Dios está presente en toda entidad como fundamento de esta. Dios es el principio sin principio del que ha brotado, por libre creación, la vida. La noción "presencia esencial", que sjc retoma de santo Tomás de Aquino, tiene el mismo sentido que nuestra expresión "principio sin principio". La diferencia entre ambas es que mientras la segunda abre la posibilidad de confundir al Dios de la revelación con el de la teodicea, la primera impide la falsa identificación entre el ser de Dios y el de los entes. En el contexto de la experiencia místico-religiosa, como señala san Agustín:

[...] el poder del Creador, su fuerza omnipotente y omnisciente, es para todas y cada una de las criaturas, la causa de su continuada existencia, y si esa fuerza cesase en algún momento de dirigir las cosas que han sido creadas, en un solo y mismo instante sus formas dejarían de ser y su naturaleza entera perecería. (San Agustín, 1947 , pp. 4, 22, 22)

En el contexto de la experiencia mística, "'trascendencia de Dios' no significa lejanía de la realidad y de las personas. Precisamente por ser absolutamente trascendente puede ser y es inmanente en la totalidad de lo real haciéndolo ser,

1 No hay nada más lejano a la experiencia mística como la noción de causa sui. Para el pensamiento moderno, dada la finitud de todo lo que existe, de ello se sigue que no pudiendo ser la causa de su existencia ni de su conservación, todo cuanto existe ha de tener su fundamento en una entidad de mayor jerarquía. Para evitar la postulación de una serie infinita de fundamentos, la especulación se detiene y postula la existencia de un ente absoluto, causa de todo lo que existe, así como de sí mismo. Puesto que para la metafísica moderna Dios es un ente, o no tendrá fundamento, o será fundamento de sí mismo. / Mientras que la metafísica moderna se empeña en demostrar a Dios como fundamento de sí mismo y del mundo, la mística pone al descubierto que Dios es, como advierte Juan Martín Velasco, una presencia inobjetiva, que sostiene al hombre y a las cosas sin necesidad de ser Él mismo sostenido. Afirmación donde el término "sin", lejos de nombrar una carencia, designa una realidad que sobrepasa el plano óntico: un ser trascendente. 
'dándole de ser', o con otra imagen, fundamentándolo" (Martín Velasco, 2009, p. 76). Ya que, "en Dios tenemos nuestra vida y nuestro movimiento y nuestro ser [...] el alma ve que tiene su vida natural en Dios y el ser que en Él tiene" (De la Cruz, 2003a, 8, 3).

De acuerdo con sJc, la dimensión más profunda de la existencia humana, a la que llama el "centro del alma", alberga la presencia del Dios Trinitario. Al respecto, afirma que "el Verbo, Hijo de Dios, juntamente con el Padre y el Espíritu santo, esencial y presencialmente está escondido en el íntimo ser del alma" (2003a, 1, 6). Lo anterior significa que, al mismo tiempo, pero bajo diferente aspecto, Dios es trascendente e inmanente respecto del hombre.

Dios es trascendente porque constituye la fuente de la vida, y en este sentido está más allá de toda facticidad, como su causa; como la realidad infinita cuyo ser - en contra de lo que sostiene la metafísica - no comparte la condición de ser del ente, por cuanto entre Dios y las criaturas hay una semejanza que no es recíproca. Diferencia en razón de la cual, el discurso testimonial de los místicos habla de Dios como presencia y no como entidad.

En otro sentido, Dios es inmanente, porque al crear la realidad no lo ha hecho, como el demiurgo platónico, imitando modelos o arquetipos eternos de los entes; ha creado al mundo y al hombre tomando como modelo al Hijo. Refiriéndose al Verbo, el Evangelio según san Juan afirma que "Todas las cosas por Él fueron hechas; y sin Él nada de lo que es hecho, fué hecho" (Jn 1, 3). Si en el Cántico espiritual sjc celebra la belleza y perfección de la Creación natural, comparándola con un bosque planteado por la mano del Amado, es porque sabe - por experiencia propia y gracias a la revelación - , que el Padre ha creado a la esposa y su palacio; al hombre y a la naturaleza, tomando como modelo al Hijo. Para sJC, las criaturas son testimonios o reflejos finitos de lo divino. Por ello, sjc señala que "el alma mucho se mueve a el amor de su Amado Dios por la consideración de las criaturas" (2003a, 5, 3).

Ahora bien, si Dios es al mismo tiempo, pero no bajo el mismo aspecto, trascendente e inmanente, la pregunta obligada es: dado que está presente en todo hombre, sosteniéndole en la existencia, ¿por qué solo el místico participa de dicha experiencia? La respuesta es que "Dios en todas las almas mora en secreto y encubierto en la substancia de ellas" (De la Cruz, 2003b, 4, 14). La presencia de Dios no es la de un objeto dentro de otro, sino la de una realidad inobjetiva que mora en otra, como fundamento suyo, a la que no es posible aprehender por medio de ningún acto de representación, en razón de su ser sobrenatural.

\section{La presencia de dios en el centro del alma}

Toda vez que sJc no es teólogo ni filósofo, tampoco desarrolla una antropología ni una metafísica originales. Al hablar del hombre, el santo se vale de las 
categorías filosóficas de su época, no porque piense que la experiencia de Dios está comprometida con la filosofía platónica, agustiniana o aristotélico-tomista, sino porque esas y no otras fueron las ideas que, al formar parte de su horizonte de comprensión, le permitieron nombrar su encuentro con el Amado. Como ha señalado un denotado intérprete de SJC, "Sus experiencias místicas no nacen de su filosofía, pero en ella descansa la explicación que dio el maestro a su experiencia" (De Jesús Sacramentado, 1929, p. 102).

El santo piensa y habla a partir del horizonte de comprensión que le es propio. Por lo que se refiere a la distinción de elementos que integran al ser del hombre (sentidos exteriores, interiores, entendimiento, voluntad y memoria), su antropología carece de originalidad. Siempre que la escolástica le permite dar cuenta de la actitud religiosa, sJc retoma dicho discurso.

Ahora bien, aun cuando la escolástica basta para explicar que el hombre es capaz de elevarse al conocimiento y al amor natural o erótico de Dios, no permite comprender la unión de semejanza amorosa en la que culmina el proceso místico. Tal deficiencia conduce a sjc a abandonar el lenguaje de la escolástica y a echar mano de metáforas y comparaciones diversas, aderezadas para explicar que la presencia escondida de Dios en el hombre es el principio de la unión mística.

Con tal propósito en mente, al hablar del alma, sjc se vale de imágenes que dan origen a una peculiar topografía, donde cada sitio nombra una posibilidad de encuentro con Dios, a la que corresponde un peculiar modo de existencia. En primer lugar, haciendo uso de una topografía vertical, el santo afirma que el "espíritu" es la parte superior del alma, mientras que designa al "sentido" como la parte inferior de esta. A partir de esta imagen, el camino de perfección se comprende como ascenso. En segundo lugar, a la descripción del "fondo del alma" o del "centro del alma", como el lugar donde mora escondida la presencia de Dios, subyace una topografía concéntrica, que permite comprender el proceso místico como un tránsito de la periferia al centro.

Mientras que al referirse a las potencias y sentidos del alma, el santo retoma la división agustiniana, al hablar del centro del alma, adopta una perspectiva original. En ambos casos, la finalidad de las imágenes es indicar que el hombre puede adoptar diversos modos de existencia, que se distinguen entre sí en función de su grado de proximidad, ya sea al fin sobrenatural de la unión con Dios o al de la afirmación egoísta de sí mismo. El hombre es un ser unitario: no hay una separación tajante entre las estructuras que lo conforman. En sí misma,

[...] el alma en cuanto espíritu no tiene alto ni bajo, más profundo o menos profundo, en su ser [...] pues en ella no hay partes, no tiene más diferencia dentro que fuera, que toda ella es de una manera y no tiene centro de hondo y menos hondo de cuantitativo. (De la Cruz, 2003b, 1, 10)

Sin embargo, es posible distinguir sentidos y facultades a través de la observación de los poderes del alma. Estructuras a las que cabe juzgar de más exteriores 
o interiores, según tengan una relación estrecha o lejana con la presencia del Dios, que la imagen ubica en el centro del alma.

De acuerdo con las enseñanzas de san Agustín y sjc, el que ama se hace semejante a aquello que ama. Quien ama el mundo se hace mundo y quien ama a Dios deviene Dios por participación. Así como es el objeto y el grado de perfección de su amor, así es el hombre. Cuando el hombre vive entregado a proyectos mundanos, difícilmente cae en la cuenta de la existencia de Dios y de su ser ante Dios. En tal caso, no solo desconoce a Dios como origen de su existencia, sino también se desconoce a sí mismo.

El poeta místico compara el extravío de la voluntad en los placeres mundanos con el movimiento que conduce al hombre fuera de sí mismo. Al descenso que hace al hombre quedar embebido en el goce de las criaturas en olvido del Creador, se opone la vía mística como un ascenso del alma a Dios. Progresar en el camino de perfección es subir. Y la contemplación es la "secreta escala" a través de la cual "sube el alma a conocer y poseer los bienes y tesoros del cielo" (De la Cruz, 2003c, 2, 18, 1).

Por ser criatura, el hombre alberga la presencia esencial de Dios, que lo sostiene en la existencia. Que Dios sea inmanente al hombre significa que el hombre participa del ser de Dios, hasta tal punto que está en condiciones de asemejarse a él, de descubrir su identidad esencial con Dios, una vez purificadas todas las estructuras de su ser.

La enseñanza central de la antropología sanjuanista es que el hombre es un ser para-Dios, al que la gracia habilita para que pueda participar de las operaciones que definen el ser de Dios: conocerse y amarse a sí mismo, en cada una de las Personas de la Trinidad, con el mismo amor ágape que Cristo amó al hombre en la cruz. Ahora bien, ¿cómo puede ser eso posible? sjc responde: porque en su ser más originario - en el centro de su alma - el hombre es Dios.

Aunque en diferentes lugares de su obra el santo hace mención de este nivel profundo y esencial de la existencia, es sobre todo al comentar los versos 9 al 16 de la primera canción del poema Llama de amor viva B, cuando explica el significado de la expresión "centro del alma". En primer lugar, señala que mientras más purificada está un alma, más interior se dice que es, porque menos interesada está en lo que pasa fuera de ella. La pureza es la condición de posibilidad de la comunicación amorosa con Dios. El alma pura está vacía de todo apetito, llena del amor divino.

Cuando el santo dice que "El centro del alma es Dios" (2003b, 1, 12), lo que pretende dar a entender es la condición de posibilidad de que toda alma puede conocer a Dios y participar del ejercicio del amor perfecto, porque al crearla, Dios la pre-destinó a esta visión. Y para que pudiera llegar a ella, la redimió de sus pecados, habilitándola para poder acoger la noticia regeneradora de la fe contemplativa. 
El "centro del alma" o "la substancia del alma", como también lo llama sjc, designa tanto el lugar donde mora la presencia divina como el encuentro con aquella, ${ }^{2}$ al que el hombre accede cuando, tras haber aprendido a esconderse en sí mismo para a recoger sus afectos en Dios, recibe la merced del matrimonio espiritual. ${ }^{3}$ Por lo que se refiere a la primera cuestión, el "centro del alma" es la estructura ontológica que alberga la presencia escondida de Dios, que a su vez permite comprender por qué el hombre desea la unión amorosa en la que desemboca el proceso místico. Para comprender por qué el "centro del alma" es el "lugar" donde se realiza "la divina junta y unión del alma con la substancia divina" (2003d, 2, 24, 4), es preciso recordar que Dios no es entidad; es presencia transformadora. Presencia que solo se torna manifiesta cuando el hombre está en condiciones de vislumbrar el acontecer de lo divino, en medio de la vida cotidiana.

En la afirmación recién citada de sjc, "sustancia del alma" y "sustancia divina" nombran respectivamente el ser esencial del hombre y la realidad esencial de Dios. Propiamente, se trata de dos realidades distintas. Sin embargo, por cuanto la experiencia mística cristiana posee un carácter unitivo, y el amor tiene el poder de igualar amada y Amado, de ello se sigue que el místico es Dios por participación. Puesto que, en palabras de san Pablo, el místico ya no es más él mismo, sino que es Dios quien vive y obra en él, tampoco cabe ya mantener la distinción entre Amado y amada. El fruto de la unión es, conforme a las canciones de la Noche oscura, "amada en el Amado transformada".

De acuerdo con sJc, se llama "centro más profundo [...del alma] a lo más que puede llegar su ser y virtud y la fuerza de su operación y movimiento" (2003b, 1,10 ). El alma (que en este contexto ha de entenderse como un modo de significar al hombre) está en su más profundo centro, cuando sus obras expresan el acto y el hábito de las virtudes teologales sobrenaturales - cuya infusión lleva aparejada el hábito y el acto de las virtudes morales sobrenaturales-.

El centro del alma no es un lugar, sino un modo de existencia; una modalidad fáctica del ser en el mundo, un modo de vida al que se llega una vez que han desparecido todos los obstáculos que antes le habían impedido caer en la cuenta de que el reino de Dios habitaba en su interior. Solo a la luz de tal interpretación cobran sentido las palabras de sJc:

El centro del alma es Dios, al cual cuando ella hubiere llegado según toda la capacidad de su ser y según la fuerza de su operación e inclinación habrá llegado al último y más profundo centro suyo en Dios, que será cuando con todas sus fuerzas entienda, ame y goce a Dios. ( 2003b, 1, 12)

2 Reconocer que es así reviste una gran importancia para la comprensión de la mística en tanto que conocimiento amoroso y de Dios como presencia inobjetiva que habita en cada hombre. A diferencia de la teodicea, la mística está lejos de confundir a Dios con un ente.

3 Dispersión y recogimiento son movimientos opuestos, a los que corresponden dos modos de vida radicalmente distintos: el extravío en el goce de los bienes finitos y la búsqueda de la presencia divina, a solas y en silencio, en olvido del mundo y de sí mismo. 
Con todo, es preciso recordar que el alma puede llegar a ser "simílima a Dios en pureza sin tener en sí ninguna mezcla de imperfección; y así se puede hacer pura transformación por participación de unión, aunque no esencialmente" (2003d, 2, 5, 5).

\section{El hombre carnal y el hombre espiritual}

Si Dios está escondido en el centro del alma, ¿cómo es que no nos percatamos de su presencia? El problema no es que Dios esté ausente, que haya huido o que ya no nos dirija palabra alguna para convocarnos a la vida eterna. Lo que ocurre es que no tenemos tiempo para Dios. No es que el don del amor divino deje de otorgarse a todos por igual; ocurre que al no estar allí para recibirlo, lo perdemos.

El Dios del cristianismo es un Dios escondido. Una realidad trascendente cuya grandeza y perfección solo se manifiesta veladamente. En esta vida no es posible acceder a la visión clara y esencial de Dios. A causa de la desproporción entre su ser y el nuestro, la única manera de acceder a su experiencia personal es a través de la fe teologal. La contemplación es el único medio proporcionado al fin sobrenatural de la existencia: la unión de semejanza amorosa con Dios.

Al referirse al hombre, sJc deja en claro que la existencia está atravesada por dos dimensiones que, al expresarse en actos, discursos y expectativas, dan origen a dos orientaciones vitales opuestas: carne y espíritu. A pesar de que el hombre es un ser unitario, ello no implica que las operaciones ni los deseos asociados a cada una de estas dimensiones armonicen con el otro. Por el contrario, aquello que la experiencia pone de manifiesto es que la vida es una constante tensión entre las tendencias de la carne y las del espíritu.

Carne y espíritu no son substancias separadas; son dimensiones de la existencia concreta, que al no estar aisladas, mantienen entre sí una relación de pugna: cada una busca arrastrar a la otra en su movimiento hacia lo mundano y hacia lo transcendente. En virtud de nuestra condición encarnada, estamos dotados de sentidos. Pero los sentidos no solo nos aportan noticias sobre los entes circundantes. La noticia sensible provoca un movimiento de placer y displacer en la voluntad; movimiento que aun cuando por sí mismo es moral y espiritualmente neutro, constituye un riesgo de alienación, porque a través suyo surgen los apegos.

Si entre la carne y el espíritu hay ruptura y conflictividad, es debido a que cada una apunta a un movimiento distinto, que avanza hacia direcciones opuestas, dando origen a dos inclinaciones que se expresan en dos modos de vida distintos. Como señala sjc, "la parte sensitiva se mueve respecto a las criaturas y a lo temporal [...] y la superior y racional respecto a Dios y a lo espiritual" (2003d, $2,4,2)$. Si la vida del hombre carnal - cuyo criterio de acción es el gusto del 
sentido- es "inferior", es debido a que la presencia salvadora del Misterio de Dios no puede ofrecerse a los sentidos.

Quien se detiene en el gusto de los bienes sensibles asume un modo de vida carnal. Su modo de ser y de habitar el mundo está determinado por las apetencias que surgen en él, a consecuencia del contacto con aquello que le sale al paso en la experiencia. Al referirse a tal tipo de hombre, sjc sostiene que "El hombre que busca el gusto de las cosas sensuales y en ellas pone su gozo no merece ni se le debe dar otro nombre que estos que habemos dicho, a saber: sensual, animal, temporal, etc." (2003d, 3, 26, 3).

Por su parte, se dice "espiritual" la existencia de aquel cuya intención última - que se concreta en sus palabras y acciones - es la unión con Dios. El espíritu es "la porción superior del alma, que tiene respecto y comunicación con Dios" (2003d, 3, 26, 4). El espiritual es el que entiende de las cosas de Dios; el que está capacitado para reconocer su presencia escondida en el centro del alma, porque tiene sus potencias recogidas y orientadas hacia Dios y no hacia los bienes mundanos.

El principio que hace posible la distinción entre el modo de vida carnal y el espiritual es la libertad. Si el hombre no fuera capaz de elegir y de elegirse, la distinción entre ambos modos de existencia tendría un carácter descriptivo, pero no normativo. Carecería de sentido que los místicos nos invitaran a superar el plano natural de la vida, para abrirnos a la vida sobrenatural, si no todos estuviéramos en condiciones de hacerlo.

Carne y espíritu son orientaciones vitales que dan origen a proyectos que se oponen mutuamente. Quien vive entregado al goce de los bienes finitos y empeña su voluntad en la posesión egoísta de aquello que le provoca placer, que refuerza su inclinación a tomar la satisfacción personal como criterio de acción moral, no puede participar de la experiencia de Dios. En el mejor de los casos - que en otro sentido es el peor-, Dios será para tal tipo de hombre el término máximo al que se refiere su capacidad de disfrute; será el mayor de los bienes posibles, lo que implica que para haber llegado a esa conclusión, tuvo que haber hecho una comparación del ente "Dios" con los entes finitos. Lo cual es grave agravio para Dios, que con ninguna otra cosa tiene paralelo, en razón de su trascendencia.

El hombre carnal o, como dice el santo, el "animal hombre", es el que solo usa el sentido para dirigirse a Dios. Es aquel para quien el ser trascendente de Dios está oculto bajo los vicios e imperfecciones que ocupan su alma. A esta idea hace referencia sjc cuando dice que "El hombre animal no percibe las cosas que son del espíritu de Dios porque son locura para él, y no puede entenderlas porque son ellas espirituales" (2003d, 2, 19, 11). La razón de esta sentencia es que el principio de conocimiento es la semejanza entre el objeto del conocimiento y el medio que se usa para alcanzarlo. 
Se denomina hombre carnal o animal al que, no habiendo negado los movimientos desordenados de su sensualidad, está lleno de imperfecciones y apetitos. ${ }^{4}$ Según sjc: "es imposible que el hombre, si no es espiritual [esto es, si es carnal], pueda juzgar de las cosas de Dios ni entenderlas razonablemente, y entonces no es espiritual cuando las juzga según el sentido" (2003d, 2, 19, 11).

Puesto que carne y espíritu designan disposiciones existenciales opuestas, el amor que el Dios del cristianismo otorga al hombre, a cuya correspondencia convoca, es exclusivo y excluyente de cualquier otra adoración. Al hombre religioso - y con mayor razón al místico- no le está permitido dispersar su atención amorosa en diversos objetos. El que comprende que solo Dios es y, como afirmaba santa Teresa de Jesús, "Sólo Dios basta", reserva su deseo para Dios.

Tanto para san Agustín como para sJc, el amor tiene el poder de igualar al hombre con el objeto amado. Al hombre que ama al mundo se le llama "mundano", porque su interés y proyectos están dirigidos a hacerse uno con él; a extraviarse tanto en los bienes finitos como en los negocios cotidianos. Por el contrario, se llama "espiritual" a quien, no poniendo sus gustos ni contentos más que en Dios, no se derrama en el mundo. De acuerdo con la antropología mística de sJc, existe un dinamismo de la vida, por obra del cual, el hombre puede identificarse con aquello en lo que coloca su voluntad. No somos carne ni espíritu, pero tenemos el poder de vivir carnal o espiritualmente.

Dado que otro principio de la concepción del conocimiento de sjc es que lo semejante conoce a lo semejante, de ello se sigue que el hombre carnal no tiene capacidad para comprender cuestiones espirituales; del mismo modo que para el hombre espiritual, los afanes y goces del hombre carnal no pasan de ser naderías por las que toda perfección se pierde.

A causa de su identificación con las realidades mundanas, el hombre carnal - que es quien no se percata de la presencia de Dios en él- no puede caer en la cuenta de que su existencia tiene por principio a Dios. Ello explica que, aun habitando en el centro de su alma, Dios sea para tal hombre una presencia nula, que no figura entre sus preocupaciones intelectuales.

Si el hombre carnal no puede comprender el misterio de Dios, que corresponde al plano espiritual, no es porque en él haya algún tipo de limitación intelectual, sino porque su afectividad está orientada al mundo, y ello lo coloca en un temple que le impide dirigir su deseo a Dios y estar dispuesto a negar sus imperfecciones por amor a Él. Cuando el hombre carnal oye hablar acerca del Misterio de Dios, es como si no lo hiciera, porque solo alcanza a vislumbrar aquello que tiene proporción con el sentido, que se acomoda a sus afanes y apetitos.

4 El apetito es un movimiento accidental de la voluntad, que surge del deseo desordenado. Si los petitos fueran movimientos derivados de una determinación ontológica, su aniquilación sería imposible. Sin embargo, en razón de su ser accidental, los apetitos pueden ser aniquilados, sin que ello suponga algún daño en el hombre. Para una fenomenología de los apetitos, véase: González, L., (2015). Amor y negación en san Juan de la Cruz: el sentido cristocéntrico de la negación de los apetitos en el primer libro de la Subida del Monte Carmelo. Revista Española de Teología, (75), 259-289. 
Por lo cual, los que no son tan espirituales que estén purgados de los apetitos y gustos, sino que todavía están algo animales en ellos, crean que las cosas más viles y bajas al espíritu, que son las que más se llegan al sentido según el cual todavía ellos viven, las tendrán por gran cosa; y las que son las que más preciadas y más altas para el espíritu, que son las que más se apartan del sentido, las tendrán en poco y no las estimarán. $(2003 b, 3,7,4)$

Más aun, sjc coincide con san Pablo en la afirmación de que el antagonismo entre cuerpo y espíritu se radicaliza a causa del pecado. En más de una ocasión, el santo recuerda lo dicho por san Pablo (Gal 5, 7), acerca de que la carne resiste al espíritu. Y sostiene que la necesidad de la purgación, tanto pasiva como activa, radica justamente en su finalidad: mortificar la carne para que, reorientado hacia el espíritu e ilustrado por la noticia amorosa de la fe, el hombre pueda conocer y gozar a su modo de la presencia divina, en vez de impedirla, llevando la voluntad del hombre hacia otro rumbo. Así, desde cierta perspectiva, el proceso místico es un tránsito del sentido al espíritu.

\section{Conclusiones}

Lo que a sjc le interesa no es generar un Tratado del Hombre, sino mostrar que la grandeza humana radica en su apertura al Misterio de Dios. La suya no es una antropología que tenga su finalidad en ella misma, no es un desarrollo teórico que busque simplemente comprender al hombre. Lo que el santo quiere es explicar por qué el hombre es interlocutor de Dios, para dejar en claro que, conforme a la revelación y a la experiencia mística - que se expresan en discursos originarios sobre el acontecer de lo divino y, en tal sentido, se distinguen de la teología y de la teodicea - , el hombre ha sido creado a imagen de Dios, pero solo si logra despojarse de todo lo que estorba e impide su transformación de semejanza con el Esposo Cristo, su vida se convierte en manifestación de la presencia salvadora de Aquél.

Más que apuntar hacia ciertas estructuras psicológicas, el discurso de sjc retoma la antropología escolástica para dar cuenta del ser del hombre; la abandona, cuando lo que se propone es explicar que la condición de posibilidad de la experiencia mística en la presencia de Dios, escondida en el centro del alma. Así, "San Juan de la Cruz, aunque teólogo, no hace sólo teología. Muestra un camino filosófico hacia la manifestación del fenómeno pleno" (Arboleda, 2006, p. 323).

Además de ser una estructura del ser del hombre, el “centro del alma" designa un modo de existencia a la que el hombre llega tras haber pasado por los aprietos y las sequedades de las purgaciones activa y pasiva del sentido y del espíritu. El "centro del alma" no es una potencia humana: por un lado, es la condición de ser del hombre que explica su capacidad para entrar en relación con Dios; por el otro, es un modo de vida, cuya principal característica es que el hombre deja 
de estar centrado en sí mismo para abrir paso a la manifestación de lo divino, en cada uno de sus actos y renuncias, discursos y silencios.

Mientras que el hombre profano vive apartado de la salvación, puesto que sus afectos y preocupaciones se relacionan con lo que ocurre en la parte más exterior del alma, el místico tiene una vida "substancial", porque participa de la noticia sobrenatural de Dios. El místico mora en la substancia del alma: es allí a donde se dirigen sus inquietudes y deseos, donde recibe la iluminación de la fe y los toques y sentimientos espirituales que el contacto con Dios provocan en el sentido (De la Cruz, 2003a, 24, 4).

Místico es aquel que tiene un encuentro personal con la presencia inobjetiva de Dios y que se conoce, por experiencia propia, que su ser y existencia están sostenidos por el principio sin principio al que las Sagradas Escrituras definen como amor ágape. Tal es el sentido de la sentencia joánica: "Dios es amor: y el que permanece en el amor permanece en Dios y Dios en él” (1 Jn 4, 16).

\section{$\mathbf{R}_{\text {eferencias }}$}

Arboleda, C. (2006). La mística como proceso fenomenológico. Cuestiones Teológicas, 33(80), 315-335.

De Hipona, A. (1947). De Genesi ad litteram. En Obras completas (T. 15). Madrid: Biblioteca de Autores Cristianos.

De la Cruz, San Juan. (2003a). Cántico espiritual B. En San Juan de la Cruz, Obras completas (pp. 689-942). Burgos: Monte Carmelo.

De la Cruz, San Juan. (2003b). Llama de amor viva B. En San Juan de la Cruz, Obras completas (pp. 943-1292). Burgos: Monte Carmelo.

De la Cruz, San Juan. (2003c). Noche oscura. En San Juan de la Cruz, Obras completas (pp. $\quad$ 535-685). Burgos: Monte Carmelo.

De la Cruz, San Juan. (2003d). Subida del Monte Carmelo. En San Juan de la Cruz, Obras completas (pp. 150-527). Burgos: Monte Carmelo.

De Jesús Sacramentado, C. (1929). San Juan de la Cruz. Su obra científica y su obra literaria (Vol. 1). Madrid: Mensajero.

Cabrera, I. (2006). Para comprender la mística. En I. Cabrera y C. Silva (comps.), Umbrales de la mística (pp. 7-23). México: Universidad Nacional Autónoma de México.

González, L. (2011). Del concepto onto-teo-lógico de Dios a la comprensión fenomenológica de lo divino. Revista de Filosofía, 131(43), 121-134. 
González, L., (2015). La doctrina de Tomás de Aquino sobre la analogía como recurso para el conocimiento natural de Dios. Una meditación filosófica sobre sus límites y alcances. Perseitas, 3(2), 154-174.

Heidegger, M. (1988). Identidad y diferencia. Barcelona: Anthropos.

Heidegger, M. (2001). La frase de Nietzsche "Dios ha muerto". En Caminos de bosque. Madrid: Alianza.

Marcel, G. (1964). El misterio del ser. Buenos Aires: Sudamericana.

Martin, J. P. (2002). “Religión y teología”. En F. Diez de Velasco (comp.), Enciclopedia Iberoamericana de Religiones. El estudio de la religión (T. 1). (pp. 227-255). Madrid: Trotta.

Martín Velasco, J. (2009). Hacia una fenomenología de la experiencia de Dios. En P. Cebollada(comp.), Experiencia y misterio de Dios. Congreso internacional en el 25 aniversario del Instituto Universitario de Espiritualidad de la Universidad Pontificia de Comillas (pp. 63-104). Madrid: Universidad Pontificia de Comillas.

Melero, J. M. (2000). A vueltas con la teodicea. Revista de la Facultad de Educación de Albacete, (15), 79-91.

Otto, R. (2007). Lo santo. Lo racional y lo irracional en la idea de Dios. Madrid: Alianza. 